veterinary use is being investigated further. A fuller account of the results obtained is being prepared for publication.

${ }^{1}$ Slade, R., Chemistry and Industry, 314 (Oct. 18, 1945).

' Harbour, J. E., and Watt, J. A., Vet. Rec., 52, 685 (1945).

'Hocking, K. S., E. African Med. J., 23, 50 (1946).

'Whitnall, A. B. M., private communication (1945-46).

${ }^{5}$ Taylor, E. L., Vet. Rec., 57, 210 (1945).

\section{$|5|=$ \\ RECENT ADDITIONS TO THE LONDON ZOO}

BY DR. EDWARD HINDLE, F.R.S.

Scientific Director, Zoological Society of London

$\mathrm{T}$ HE replacement pethe collections of animals in the care of the Loological Society of London at Regent's Parl Wd Whipsnade has' progressed much more rafally than could have been anticipated, and the ntent arrival of the largest single consignmen of animals ever to reach Great Britain will go far to complete the representation of the larger African mammals.

Contrary to general belief, very few animals at Regent's Park were killed as a direct result of enemy action, for although most of the buildings were damaged and some completely destroyed as a result of bombing, the inmates, as a rule, escaped any serious injury. However, during six years of war the number of animals has naturally become reduced, owing to normal mortality, accentuated by difficulties of feeding and shortage of staff. Very few replacements have been possible during these years, and by 1945 the collections were reduced in number, and not so widely representative as in normal times.

With the end of the War the replacement of gaps in the collection presented a very difficult problem, as, apart from the question of transport, it was no longer possible to obtain animals through dealers, many of whom had gone out of business, and all of whom were short of supplies.

The Society, as in the past, has been fortunate in receiving donations from Governments, public institutions, and private individuals, two of the most notable recent gifts being the giant panda, presented by the Szech-Wan Provincial Government, and two Kodiak bears and two Ceylon elephants, presented by Mr. Alfred Ezra, vice-president of the Society. Private gifts, however, are scarcely adequate to provide the requirements of such a large institution as the London Zoo.

The appointment, in 1945, of Mr. C. S. Webb as curator-collector of the Society has helped to solve this difficulty. Mr. Webb, an experienced and widely travelled collector, went out to East Africa towards the end of last year, and during the past fow months has been successful in getting together a very large collection of mammals, birds, and a few reptiles, which have now reached Regent's Park.

The most valuable arrivals are probably the six young giraffes, belonging to three sub-species, including two Baringo, Giraffa camelopardalis rothschildi, three reticulated, G. c. reticulata, and an intermediate form, G. c. cottoni. The two latter have never been seen alive in Britain previously.

Other ungulates of interest include a lesser kudu, Strepsiceros imberbis, which has not been exhibited since 1886; a second Thomson's gazelle (the first arrived only last year), impala, duiker, water buck, bush buck, and two oribi. Last, but by no means least, a young black rhinoceros, $R$. bicornis, will provide an example of a family that has not been seen at Regent's Park since the War.

The primates include chimpanzees, Gelada baboons, guerezas, Colobus abyssinicus, and a very fine series of Brazza's monkey, Cercopithecus brazza. Of special interest are the melanic forms of a Galago ( $G$. crassicaudatus argentatus), collected from a small area around Sotik, at the west end of the Mau escarpment of western Uganda. The typical silvery-grey form, which occurs in all the surrounding country, was never seen by Mr. Webb within this area, every specimen belonging to the black race.

The carnivores include three lions, four cheetahs, a leopard, and a lynx ; six genets, two of which are melanic forms; and four species of mongoose, one of which, Myonax sanguineus, a black-tailed species, is new to the eollection.

Edentates are represented by three aardvarks, Orycteropus capensis, a weird-looking animal of considerable interest in view of its many peculiar anatomical features.

The birds include ostriches, crested cranes, yellow necked francolins, and two examples of the secretary bird, famous for its habit of destroying reptiles, a species which has long been absent from Regent's Park. Two beautiful species of crested guinea fowl, Guttera pucherani, from Mt. Kenya, and $G$. edouardi seth-smithi, from Lake Victoria, are already on view in the Pheasantry. There are four examples of the ground horn-bill, Bucorvus cafer, and the many smaller birds include at least four species new to the collection : two weaver-birds, Pseudonigrita arnaudi and Ploceus rubiginosus, a seed-eater, Poliospiza striolata, and several examples of crimson-rumped waxbills, Estrilda rhodopyga.

The reptiles include two African pythons, $P$. sebce, and a hawk-billed turtle.

Some of the animals in this collection, including the giraffes, are already on view at Regent's Park, but others will have to undergo a period of quarantine before being exhibited. \section{ACHEULEAN CULTTURE IN KENYA N the eve of hid eturn to Kenya, Dr. L. S. B. Leakey recojded (The Times, October 4) a} further remalkallo discovery made by himself and his wife $\mathrm{jl}_{\text {th }}$ course of such archæological explorations as they were able to carry out during brief peripels of leave from war duties. In April 1942, they founll an outstanding site of the Acheulean culture of the early stone age at Olorgesailie, forty-two miles from Nairobi. While examining systematically a region of well-exposed ancient lake beds, they came upon an area thickly strewn with Acheulean handaxes and cleavers. Further search revealed a number of distinct and different strata from which these specimens were being derived by sub-aerial erosion.

In 1943, further evidence was obtained pointing to the conclusion that on this site, now known as Olorgesailie site 10, there was a series of actual living. floors or camp sites of Acheulean man such as had never been found anywhere. The floors are inter. bedded between layers of lake sediment (clays and silts) on ancient land surfaces. It was evident that in the Middle Pleistocene period Acheulean man had lived on the shore of a lake of which the water-level was not constant, but had fluctuated over a long period of time. When the waters rose, the camp was 
flooded, and had to be abandoned; when the water receded the old camp had been sealed by layers of clay and a new camp was made. The same sequence of events recurred again and again, but on each occasion the returning stone industry represents a later phase of the culture. A sequence of Acheulean culture "such as exists nowhere else" is thus made available for study. Fossilized remains of extinct mammals found here include many genera and species similar to those from Oldoway Gorge, TanganyikaElephas antiquus, the straight-tusked elephant, Hippopotamus gorgops, the hippopotamus with periscopic eyes, etc. All the bones which could contain marrow have been split to extract it, but there are no signs of fire.

Dr. Leakey's discovery would appear to open up a new vista in the study of the early stone age and will, with the discovery of the Rusinga jaw recently announced, prove of high importance in the annals of the study of primitive man. It may be pointed out, however, that a discovery very similar to that now recorded by Dr. Leakey, and also showing the cultural sequence, was made at Whitlingham, near Norwich, in 1926-27, when J. E. Sainty and H. Halls recovered from such parts of the site as they were able to excavate 543 specimens, ranging from Chellean to Mousterian, of which 173 were hand-axes or choppers, the majority Acheulean. Prof. P. G. H. Boswell, after examining the site, in reporting on the geological evidence, concluded that probably primitive man had camped and established his workshops here on gravel banks adjoining the old channel of the River Yare. Lest the reported statement that "the Acheulean or great hand-axe culture was first found in England by Sir John Frere in 1750" should be a trap for the unwary, it should be noted that it was in 1797 that John Frere, F.R.S. (1740-1807), the famous antiquary-he was neither knighted nor a baronet-- discovered flints "evidently weapons of war" but now identified as Acheulean at Hoxne in Suffolk. The first recorded hand-axe found in Britain came from Gray's Inn Lane, London, in 1690 and is now in the British Museum.

Archæologists attending the forthcoming PanAfrican Congress on Prehistory at Nairobi in January next (Nature, April 20, p. 548) will have the advantage of discussing the evidence of Dr. Leakey's war-time discoveries, including the Rusinga jaw, on the actual ground. No doubt argument there will clarify the issues in the recent tendency of opinion on the place of man's origin to swing back from Asia to Africa. It should certainly serve to integrate the problems of African prehistory, and in particular to place recent discoveries in both East and South Africa in true perspective.

\section{6 \\ RESEARCH AND THE SMALLER FIRM IN BRITAIN}

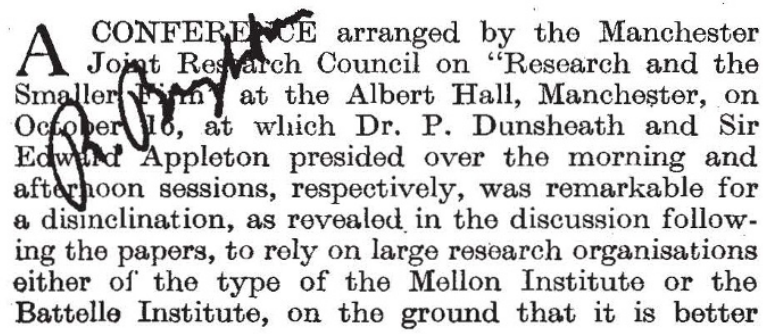

for individual officers of small concerns to make themselves responsible for research. Opposition to institutions such as the Mellon Institute with its system of industrial fellowships sponsored by individual firms was brought to a focus in Dr. F. C. Toy's address at the afternoon session on "Existing and Potential Facilities for Research". In so far as the Mellon Institute is largely supported by the large firms, the soundness of the conception and the general confidence in the foundation can scarcely be questioned; nevertheless, Dr. Toy's paper indicated concern as to the future of the research association in Great Britain and its ability to win the confidence of the industry it served.

Mr. C. G. Renold's paper at the morning session, which was opened by Mr. A. H. S. Hincheliffe, dealt with internal organisation for the application of research, and discussed more particularly the management factor which is involved, as well as a scientific attitude of mind on the part of the leaders of industry and adequate facilities for the prosecution of research, to enable industry in Britain to be more responsive to the discoveries of science. The management problem involves three phases-recognition, investigation and application-and the responsibility for pursuing such work in all phases should rest on one individual, designated by Mr. Renold as the 'development officer'. That officer's duties as regards recognition and investigation present no great difficulty from the point of view of organisation, though even here it is open to doubt whether he can be really effective unless he has the status of a director. His duties in regard to application involve relations with the manufacturing side of the business and call for special techniques and practices of management. Mr. Renold had mainly the engineering industry in mind, but what he had to say about a foundation of authoritative specifications for raw materials, products and processes based on consultation with all concerned would apply to other industries as well. Mr. Renold would vest in the development officer the custody and upkeep of such specifications and the chairmanship of consultations in either formulation or revision.

Dr. C. J. T. Cronshaw's paper, "Technical Servicethe Vital Link between the Producer and the Consumer", developed further some ideas implicit in his Mather Lecture to the Textile Institute last year, and he insisted that technical service has as its essential function the experimental investigation of the application of certain products within a consuming industry; its real value arises out of the unique knowledge acquired by research and experiment in its own laboratories. It is an abiding process of acquiring new knowledge, and it is not the function of technical service merely to provide a knowledge of the general science of chemistry, physics or engineering to a section of industry needing it. Dr. Cronshaw asserted that the function of technical service is to supply precise, specific and unique knowledge, and he then passed on to the quality of expert: ness. In doing so, he paid tribute to the skill and experience of the textile industry in Great Britain, and said that the only sure method of determining whether or not a new synthetic fibre would be a worthwhile addition to the range of fibres used by the textile industry is to put an appropriate quantity at the disposal of the industry and seek the initiative as well as the diversity of skill and talent of the firms within the industry. Sustained systematic search for novel products designed for some specific 